\title{
Interpersonal Communication between Teachers and Students by Smartphone
}

\author{
Yonglin Liang \\ School of Information Science and Engineering \\ Shaoguan University \\ Shaoguan City, China \\ liangyonglin@126.com
}

\author{
Le Kang \\ School of Information Science and Engineering \\ Shaoguan University \\ Shaoguan City, China \\ sgufedu@163.com
}

\begin{abstract}
The paper is mainly to study the influence and the teacher-student relationship of using mobile phones during the class by conducting questionnaires. In the study, we choose the freshmen to senior students who studying in one University in Guangdong province as samples. According to the survey, mobile phones were able to break traditional interactive teaching, bring more interaction and make the atmosphere freer between teacher and students. But there are some problems, such as frosty relations, lack of trust and deeply relying on mobile phones. Therefore, the influence exerting on teacher-student interaction are positive and negative sides, and students should be encouraged to use phones appropriately.
\end{abstract}

Keywords - Teacher-student interaction; Mobile phone use; Interpersonal communication; SPSS

\section{INTRODUCTION}

The survey shows mobile phone is a must for university students, 99\% of them at least having a phone.[1] It is mobile phone with the full range of features, which is convenient and easy to carry and user-friendly that more and more college students are addicted and spend lots of time and energy on it. For college students who are pursuing of individual and free space, the phone naturally becomes an essential media to obtain knowledge, information, resources in their life, while plays an important role during the class.[2]

University students are a special group. They are in a critical stage to develop their own skills. When phone usage and class interaction are closely interwoven, the disadvantages of phone usage outweigh the advantages of that. Using phones excessively will lead to many problems, such as addiction, sense of isolation, emotional disorder and physical illness while relationships, like parenthood, couples and classmates, will be worse. Nowadays, numerous researches on addressing these problems are underway, but they are still in the start-up stage and documental supports are required.

From the above problems, this study attempts to expand and improve the use of mobile phones at home and abroad, including the use of mobile phones and the teacher-student interaction. Under the premise of reading and understanding the existing literature, this study assumes that there is a positive and negative relationship between the use of mobile phones and teacher-student interaction. According to the findings of the study, we are to discuss how to use mobile phones properly among students in the class interaction.

\section{OBJECTIVE AND METHOD}

\section{A. Objective}

This study was conducted by stratified sampling and random sampling from freshmen to senior students in Guangdong Province. A total of 320 electronic questionnaires were distributed and 300 were recovered, of which 290 were valid questionnaires and the effective recovery was $90 \%$. The subjects covered students from different majors, including biology, physics, computer, mechanical, Chinese, music, and education.

\section{B. Method}

The survey is an original questionnaire divided into four parts. The first part is to survey the use of mobile phone among students; the second part is the summary of the current situation of the use of mobile phone; the third part is about college students' dependence degree on phones and individual interviews; the fourth part relates to teacher-student interaction. This survey uses SPSS 22.0 for data statistics.

Sponsored by Collaboration Education Platform supported by Guangdong Government - Information Science and Technology collaboration education center of Shaoguan University and the Key Discipline Project of Computer Application supported by Shaoguan University. 


\section{RESULTS AND DISCUSSION}

A. Using mobile phones among students plays positive role in teacher-student interaction.

1. The current situation of the phone usage

most participants were using smart phones, except only $4.83 \%$ of them. The reason is smart phones are functional and convenient for study while $84.83 \%$ of students use phones to chat on the internet, which means mobile phone is an important tool during the class.

According to the investigation, $45.83 \%$ of students said the chief motive of using phones in the class was to interact with teachers. On the other hand, the proportion of killing the time and entertainment is respectively $16.67 \%$ and $25 \%$. In the university, students have more freedom to spend their leisure time on the phone.

From the analysis above, it can be seen that mobile phone is indispensible in teacher-student interaction. In addition, mobile phone characterized by convenience, cross-region, instance and virtuality meets their needs of interaction.

\section{Broaden the interactive space}

People are social animals, seeking to interact with others is human nature. Interaction with teachers and classmates in the class becomes their urgent needs when they, far away from home, enter the university. Meanwhile, using phones could address the issues of lack of initiative and self-centeredness. By virtual internet, college students can express their ideas freely, make new friends around the world and join in different groups based on their interests. Social software, including Weibo, INS, Wechat, QQ, provides them with broader space for interaction and breaking the limitations of traditional social through emotional exchange, and sharing video and photo.

\section{Reduce the barriers of interaction}

College students tend to pursue individual freedom, strong sense of self-consciousness and novelty, while the use of phone in the class for teacher-student interaction can break the limitation of authority and the interaction is varied. Under such cases, the teacher-student interaction enters into a new pattern, breaking down the psychological, social and cultural barriers of traditional class mode. What's more, the use of mobile phones for classroom interaction, people can use a variety of forms to express their ideas and feelings, avoiding face-to-face interaction or embarrassment. And most of social software offers anonymous communication, so that both sides have a certain sense of security and privacy, which helps some college students with social barriers have smooth communication and access to good teacher-student relationship.

\section{B. Using mobile phones among students plays a negative role in teacher-student interaction.}

1. The relationship between teacher and students is not closely related.

It is very weird that scores of people absorb in their phones whether walking, eating or waiting for bus. They can't live without Wi-Fi. Peer communication starts by phone as well as ending with phone. As a result, they find it very difficult to pour out their heart with somebody. The more they use mobile phones, the worse their relationships are. On the other hand, some of them begin to be disgusted with blessing messages, because they are not honest and the messages are not written by them. Unlike the past, they are no long pay a personal visit during festivals. Under such circumstance, they are not such good friends as before anymore.

only $8.97 \%$ of them did not use phones at the party, but they had done it before and only $5.52 \%$ of them said they were more willing to use phones in accompanying families than at the party.

The Sheet 7 shows $54.31 \%$ of participants said their families and friends had complaint their using phones. $12.41 \%$ of them said the results accorded with the actual, but others said it was not true.

To sum up, most students use mobile phones on formal situations, which will lead to problem in teacher-student interaction in the class and decrease their initiative. Some of them prefer absorbing in their phones to communicating with others and are indifferent to their surroundings. For example, someone with arms pretended to kill a guy, but nobody was aware of it, because they deeply concentrated on their phones. Some pictures like this are issued on the internet. Ironically, they suffered a lot, while got stuck.

most students relied on mobile phones, in which $58.62 \%$ of them could not control their impulse using phones and the rest of them could do that and about half of students were at a loss without phones. It can be assumed that they rely too much on mobile phones, which is the main reason of negative teacher-student interaction.

\section{Short of trust}

Nowadays, numerous social networking sites adopt anonymous registration, so students can use different identities to make friends. Meantime, virtual communication allows people to enjoy the freedom of speech while also making people feel unreal. Undergraduates are lacking of social experience, and are not able to make the right judgments in the face of virtual feelings. Such news frequently reported college students were cheated. This makes college students fear teachers-student relationship and trust crisis comes, resulting in affecting the normal teachers- student interaction. 
Table I. THE COLLEGE STUDENTS’ VIEW OF “THE REDUCTION OF THE INTERPERSONAL INTERACTION IN REAL LIFE BY THE SMARTPHONE USING”

\begin{tabular}{|l|l|l|l|}
\hline \multirow{2}{*}{ The view } & \multicolumn{3}{|c|}{ Frequency and the Percentage } \\
\cline { 2 - 4 } & Frequency & Percentage & Valid Percent \\
\hline totally agreement & 28 & $9.66 \%$ & $9.66 \%$ \\
\hline moderation agreement & 137 & $47.24 \%$ & $47.24 \%$ \\
\hline uncertain & 54 & $18.62 \%$ & $18.62 \%$ \\
\hline disagree & 33 & $11.38 \%$ & $11.38 \%$ \\
\hline totally disagree & 38 & $13.10 \%$ & $13.10 \%$ \\
\hline
\end{tabular}

As the Table I mentioned, only $13.1 \%$ of students said using phones during the class did not lessen teacher-student interaction. It is clear that phone usage is a barrier to interaction.

\section{CONCLUSION}

The conclusions are as follows.

1.Firstly, mobile phone plays a vital role in their life, study and entertainment and provides convenience for them, but mobile phone addiction has caused some distress in their life.

2.Secondly, using phones in the class has a positive influence on teacher-student interaction, broaden the interactive space and lift restrictions of traditional social. More college students can get positive relations with their teacher due to their decreasing barriers.

3.Last but not least, phone usage during the class also has a negative impact on teacher-student interaction, for instance the relationship between teacher and students is not closely related and they are short of sincerity and trust during interaction. Positive teacher-student relationship exists in virtual internet, but they have problems in reality.

\section{REFERENCES}

[1] Li Xiaodong. The analysis of present situation of college students' interpersonal interaction ability [J]. Journal of Sichuan institute of technology: the social sciences,2012,(1):101-105.

[2] Feng Zhongxia.The investigation and study of College students' classroom interaction between teachers and students ability present situation [J]. Journal of Beijing University of technology: the social sciences,2004,(6):57-59.

[3] Zhang Lirui, Lan Guoshuai. The Influence and its Countermeasures of New media on contemporary college students' classroom interaction between teachers and students and its countermeasures [J]. Journal of Chongqing university of science and technology, 2013,(3):111-113.

[4] Zhang Bin, Qiu zhiyan etc. The Relationship between College Students' Loneliness, Negative Emotion and Mobile Phone Addiction [J]. Journal of Jimei university, 2015,(1):41-44.

[5] Hou Yubo. Social psychology [M]. Peking University Press, 2002.150-188. 